the third form as compared with $6 \%$ and $5 \%$ of those going in for pure science or engineering. Furthermore it was indicated that the majority of prospective medical students (79\%) were influenced in their choice of "A" level subjects by the entrance requirements to the course, while a large proportion of pure-science students ( $48 \%$ ) chose their career by virtue of "A" level attainments. This then may partly explain the unfavourable comparison in "A" level performance, the medical student having taken the examination as a means to an end whereas the actual attainment of high results at "A" level dictated the choice of the pure scientist.

The next difficulty which arises is in the assessment of the students' performance at both " $\mathrm{O}$ " and " $\mathrm{A}$ " levels of the G.C.E. There are several boards of education with inevitable variations in their standards of marking, while certain schools restrict the number of subjects to be taken at " $O$ " level. This therefore complicates the academic background of each candidate as seen from their application forms, and it is only after interview that a complete assessment is possible. Without radical changes in the general system of education little progress can be made in the present methods of selection.

Even more difficult is the task of a selection committee in making a choice of any particular student from the large number of qualified applicants. There will be inevitable biases in favour of and against any one type, but generally a committee of four is sufficient to neutralize any gross individual prejudice. It is interesting to observe that proficiency in examinations does not necessarily go hand-in-hand with personality, common sense, reasoning, and all the other attributes that are required of the complete person, and it is sad to be confronted with boys and girls who have gained academic distinction at their " $\mathrm{O}$ " level examination but who otherwise are nonentities. Parrotfashion learning reproduced for the examination is partly to blame for the unfair comparisons that are made between the early academic standards of medical and other students. On the whole the medical student often turns out to be a more interesting and informed character than his undergraduate contemporaries.

One startling change in the pattern of medical recruitment has been brought about by changes in the social structure of the country since the war. A free education in medicine is now available to anyone with the right qualifications, and no financial or social barriers need exist. However, the Oxford University inquiry indicates that recruitment into the profession is still mainly from the upper social classes (I and II). The majority of medical students had attended a public school, while Technology and the Sixth Form Boy, 1963. Oxford University Department
of Education.
2 Pickering, G., Brit. med. J., 1963, 2, 133. most of the pure-science students had been educated at a grammar school. Thus again the comparison of academic standards is complicated beyond all measure. There seems at least no reason to suppose that in medical candidates they are declining, and they may be rising. But in the scramble for places and the continual calling for better brains we must not lose sight of the final product. Medicine offers a wide variety of different jobs not all of which require the same qualities or qualifications, and those which are required are not all academic. Sir George Pickering, in his presidential address at Oxford, ${ }^{2}$ asked what it is that the wise old family doctor gives which the machine cannot. Many would agree that his reply was a timely corrective to some recent trends : "It is human sympathy and understanding that form the very core of medicine."

\section{POSTGRADUATE PREPARATION FOR GENERAL PRACTICE}

During the last decade probably about $48 \%$ of all doctors in this country have, on graduation, intended to become family doctors, though there is an impression that in the last few years this proportion has risen slightly. The undergraduate medical curriculum is constructed to provide a programme of education of university standard in the principles of medicine. None of the many changes now being introduced in schools of medicine should alter this, nor do those who advocate the foundation of a new medical school ${ }^{1}$ and see in this an opportunity to hasten change aim to do more. The purpose of pre-registration appointments is to enable all graduates to gain experience of diagnosis and treatment and of the instrumental manœuvres associated with the care of medical and surgical patients, often acutely ill, in approved hospitals. Many pre-registration posts provide additional experience in special branches allied to general medicine and general surgery, but time spent in these should be only a fraction of the total. Naturally enough at that stage most graduates who intend to become general practitioners feel themselves to lack knowledge and experience of the clinical skills, the organization, and the methods of general practice.

The only contribution which the National Health Service has made to training for general practice was the establishment of the Trainee General Practitioner Scheme in 1948. An early widespread failure to understand, with notable exceptions, that training for practice entails much more than a mere attachment as

1 Brit. med. J., 1962, 2, 592.

2 Interim Report on Experiment in Training for General Practice by the British Postgraduate Medical Federation, 1962.

s Brit. med. J. Suppl., 1963, 2, 21.

- Ibid., 1963, 1, 139. 
an assistant to a senior, sometimes very senior, principal has been followed by a reappraisal of the whole problem. In our issue this week Dr. George Swift's address (page 595) to the Association for the Study of Medical Education is a valuable analysis of much of the current thinking on these problems. Though he brings out the lack of precise knowledge on which a sound scheme of preparation can be based, our understanding is growing as a result of the work of individuals and of experiments conducted in different parts of the country, one of which, the "Nuffield Practitioner" experiment in Wessex, ${ }^{2}$ he briefly describes. The Annual Conference of Local Medical Committees this year endorsed ${ }^{3}$ a new Report on the Trainee General Practitioner Scheme ${ }^{4}$ prepared by a special committee of the General Medical Services Committee. This report represented a notable advance in thinking, and it is worth noting that it lays down no rules to restrict experiment: it positively invites innovations. For these reasons it seems capable of being adapted to meet changing ideas and circumstances.

The range and variety of services rendered by general practitioners are bound to increase as modern advances are incorporated into current practice, and this trend may be accelerated by the effect of mounting costs and staffing shortages in parts of the hospital service. Training for general practice is something in which many specialties and branches of the service must take part, and there is a post-registration phase in which a series of appointments in special branches in hospital is advisable. With the exception of obstetrics and gynaecology, for which there is no acceptable substitute for a six months' postgraduate resident appointment in a consultant unit whether or not the holder intends ultimately to practise obstetrics, there is some evidence ${ }^{2}$ that shorter periods than the usual six-months appointments can be satisfactory in certain other branches. This is easier to accept if medical education is viewed as a process continuing throughout a professional lifetime of which preparation for general practice is only a part.

Thus a new type of hospital appointment lasting for six months might be offered mainly, but not exclusively, in out-patient departments, during which a programme of duties carrying full clinical responsibility could be arranged for intending general practitioners. The grade of senior house officer might be appropriate to the professional competence of the holder, and some regional hospital boards are understood to be considering establishing appointments of this kind. Though the purpose of these would be educational, hospital authorities might welcome help in specialties in which it is now difficult to recruit junior medical staff. Enterprising house officers will no doubt gain valuable experience in other departments during their hospital appointments, and in the postgraduate medical centres set up through the generosity of the Nuffield Provincial Hospitals Trust and other bodies they should have opportunities to take part in discussions, in all of which the voice of the general practitioner should be heard.

Further training should take place from a secure base in general practice itself. The value of this should be obvious if the training period is seen as an opportunity to exercise clinical responsibility from the earliest days, coupled with chances to observe the methods of other family doctors-and indeed those of all services, statutory and voluntary, which bear on the health of individuals - and to engage in discussions and have access to ideas. Postgraduate medical centres can play a notable part here also, and it is to be hoped that their survival will be assured when voluntary support comes to an end.

Training for general practice must be as varied as general practice itself, and the opportunities now available are far from adequate, let alone ideal. There is need for research to determine what is required, how further opportunities may be created, and how coordination may be achieved between the many contributing branches and services. Departments of general practice, as they are established by universities, will obviously lead in this field, and the College of General Practitioners, already active, likewise has an important part to play. University postgraduate committees and departments of social medicine and other departments in medical schools with strong community interests could take an active part by offering co-ordinating courses to principals and to those in training in an attempt to weave into a coherent pattern all the strands of knowledge garnered from so many and such varied sources.

Gradually, it is hoped, a body of knowledge will be built up on which action can be taken with more confidence, but there will always be a need for a great variety of training opportunities to meet the varying requirements of those who intend to practise in what is potentially the widest field of the whole of medicine. At the same time no apology is needed for repeating that a plan of preparation for general practice is best made in the knowledge that this represents only one phase in a lifetime of continuing education.

\section{UNDERGRADUATE TEACHING OF PSYCHIATRY}

"In future, a medical teaching centre cannot be regarded as making proper provision for the training of medical students unless it has an active department of psychiatry, the work and teaching of which are interwoven with the work and teaching of other 